\title{
Halofantrine: a new substance for treatment of multidrug-resistant malaria
}

\author{
H.D. Nothdurft, R. Clemens, H.L. Bock, and T. Löscher \\ Abteilung für Infektions- und Tropenmedizin an der Medizinischen Klinik, Klinikum Innenstadt \\ der Ludwig-Maximilians-Universität München
}

Key words: Halofantrine - Malaria - Plasmodium falciparum - Multidrug resistance

\section{Malaria situation}

Malaria is one of the most important causes of morbidity and mortality in tropical countries. The World Health Organization considers the worldwide annual incidence of acute malaria to be 270 million infections and 110 million clinical cases [28]. The number of deaths is estimated at 1-2 million per annum. Contributing to this death rate is the particularly high fatality rate of approximately $2 \%$ in multiresistant Plasmodium falcipar$u m$ infections [21].

Since the description of the first chloroquineresistant $P$. falciparum strains in Thailand in 1959 and Columbia in 1960 [16] the problem of resistance has expanded to more than 50 countries [13]. Furthermore, resistance against the majority of currently available antimalarial agents has developed as well, especially in Africa and Southeast Asia. A 1989 study in Thailand reported that the efficacy of chloroquine was almost $0 \%$ and that of sulfadoxine/pyrimethamine less than $10 \%$. Quinine as monotherapy had an efficacy of $60 \%$ and mefloquine one of not more than $80 \%$ [6] (Fig. 1).

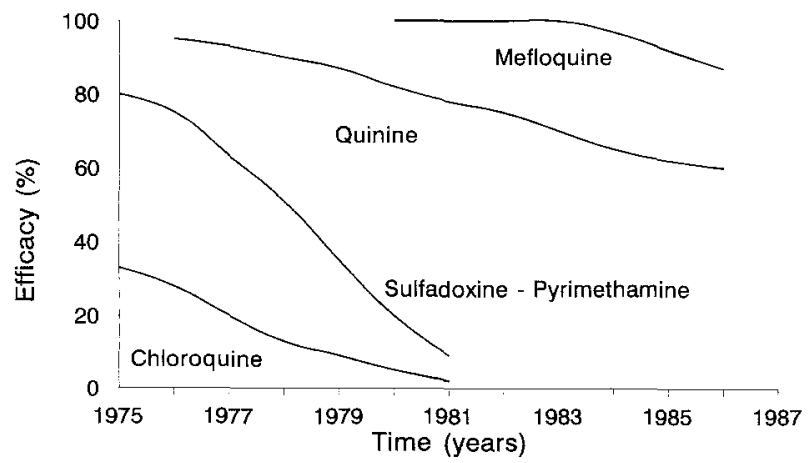

Fig. 1. Increase in resistance to various antimalarials in Thailand (from [6])
In 1986 the established combination of mefloquine with sulfadoxine and pyrimethamine, which had been introduced to delay the evolution of resistance to mefloquine, was effective in $98 \%$ of all $P$. falciparum infections. However, in a prospective study conducted in the same area in 1990, the efficacy had already dropped to $71 \%$ [14]. This increase in resistance to mefloquine may also increase the resistance to quinine because of structural similarities [24]. Due to this continuously worsening malaria situation there is an urgent need for new and, especially, structurally different antimalarial agents.

\section{Halofantrine}

The Walter Reed Army Institute for Research has tested more than 300000 substances within the scope of its antimalarial drug development program; of these, 9000 have shown potential antimalarial activity. Among the substances entering further development was halofantrine, which had been described as (a potential) antimalarial as early as the Second World War [27]. Halofantrine is an amino alcohol and belongs to the class of 9-phenantrenmethanols, which have not yet been used in the treatment of malaria. The risk of cross-resistance to other antimalarials, which in general are aminoquinolones, seems to be minor as the structure of halofantrine is basically different (Fig. 2).

Halofantrine is a blood schizontocide affecting only trophozoites and schizonts in the red blood cells. As with all other blood schizontocides, halofantrine is ineffective against the liver forms of $P$. vivax and $P$. ovale. Thus, additional treatment with a tissue schizontocide such as primaquine is indicated in these infections.

The mechanism of action of halofantrine is not yet completely understood. The substance seems to bind to ferriprotoporphyrin IX in red blood cells affected by plasmodia [3]. Further modes of action which have not yet been observed with other antimalarials may include inhibition of the proton- 


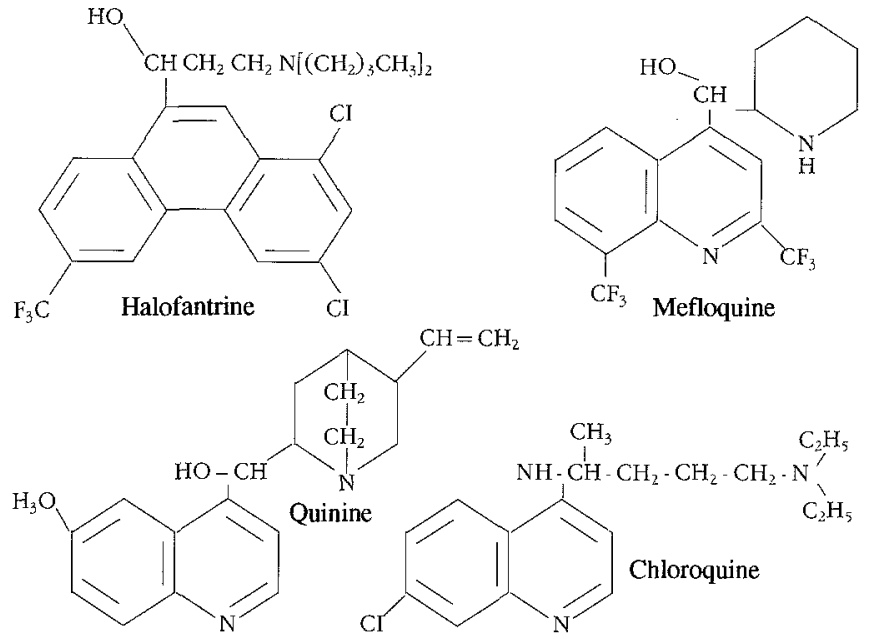

Fig. 2. Structure of various antimalarials

pump at the parasite-erythrocyte contact spot [25] as well as an effect on mitochondria and hematozoin vesicles of the Plasmodium [17].

The antimalarial efficacy of halofantrine has been demonstrated both in vivo in various rodents and primate species and in vitro. The in vitro tests were performed by determinating the uptake of radioactively labeled hypoxanthine in the erythrocyte stages of chloroquine-sensitive and chloroquine-resistant $P$. falciparum strains. The mean inhibitory concentration for halofantrine was 2.5 and $3.2 \mathrm{ng} / \mathrm{ml}$, respectively, compared to 6.7 and $7.8 \mathrm{ng} / \mathrm{ml}$ for mefloquine. For both substances cross-resistance to chloroquine can thus be excluded clinically [20]. The in vitro efficacy of halofantrine has also been verified through clinical isolates of $P$. falciparum cases from Asia and Africa $[15,26]$ (Table 1$)$.

In vitro comparisons of the mean inhibitory concentrations of halofantrine and mefloquine in 235 clinical $P$. falciparum isolates from various endemic areas did not indicate cross-resistance between the two substances. However, resistance may be induced by incubating $P$. falciparum isolates in increasing mefloquine concentrations. The mean inhibitory concentration of mefloquine thereby increases five fold, whereas the increase with halofantrine is only two fold [20].

Halofantrine is only poorly and incompletely absorbed after oral administration. Although great inter- and intraindividual differences in kinetics are evident; the maximum plasma concentration is consistently reached by about $6 \mathrm{~h} \mathrm{[5].} \mathrm{Above} \mathrm{a} \mathrm{sin-}$ gle dose of $500-750 \mathrm{mg}$ absorption of the substance does not increase further. Because of this ceiling effect and the great variability in absorption
Table 1. In vitro antimalarial activity of drugs against $P$. falciparum isolates from naturally acquired malaria infections in West Africa and Thailand

\begin{tabular}{lllll}
\hline Mean $\mathrm{IC}_{50}(\mathrm{ng} / \mathrm{ml})$ & & & \\
\hline Country & $\begin{array}{l}\text { Chloro- } \\
\text { quine }\end{array}$ & $\begin{array}{l}\text { Meflo- } \\
\text { quine }\end{array}$ & Quinine & $\begin{array}{l}\text { Halofan- } \\
\text { trine }\end{array}$ \\
\hline Sierra Leone & 4.73 & 24.50 & 53.60 & 3.90 \\
Sierra Leone & 6.39 & 18.71 & 40.09 & 3.60 \\
Nigeria & 6.91 & 15.03 & 40.33 & 1.26 \\
Nigeria & 7.20 & 11.83 & 40.80 & 0.90 \\
Nigeria & 8.41 & 17.06 & 77.99 & 4.70 \\
Nigeria & 4.73 & 32.39 & 91.15 & 2.40 \\
Sudan & 6.39 & 1.57 & 10.65 & 0.33 \\
Indochina & 6.91 & 4.30 & 90.75 & 0.45 \\
Thailand $^{\mathrm{a}}$ & 7.20 & 5.33 & 165.61 & 0.68 \\
\hline
\end{tabular}

a All cases

halofantrine cannot be used as single dose. During the dose-finding studies a dosage regime of $3 \times$ $500 \mathrm{mg}$ halofantrine at 6 -h intervals was shown to be most effective. However, absorption and pharmacokinetics of halofantrine can be improved with high-fat meals, with the $\mathrm{C}_{\max }$ being up to six fold [12]. Bioequivalence data of different formulations have revealed that absorption of the suspension is $20 \%$ lower than that with tablets and capsules. Again, inter- and intraindividual variations must be taken into account.

The main metabolite of halofantrine is an $N$ desbutylhalofantrine, which also has schizontocidal activity. The elimination half-life of halofantrine is 1-2 days, and that for the equally effective metabolite 3-5 days. Elimination kinetics and especially duration of subtherapeutic substance levels are a major determinant in the development of resistance against antimalarials. Because of the substantially shorter elimination and half-life duration of subtherapeutic levels of halofantrine compared to chloroquine and mefloquine the problem of resistance to halofantrine should be significantly less [1] (Fig. 3). Halofantrine is not suitable for prophylactic use because of its pharmacokinetics, which, again, should delay the development of resistance.

Halofantrine is neither mutagenic nor teratogenic. Because of its embryotoxicity, however, halofantrine is justified during pregnancy only for vital indications and in the absence of an alternative compound. Halofantrine had no negative impact on the major organ systems in the dose ranges tested. Unlike most other antimalarials, halofantrine does especially not interfere with the mechanism of insulin secretion, with the risk of hypogly- 


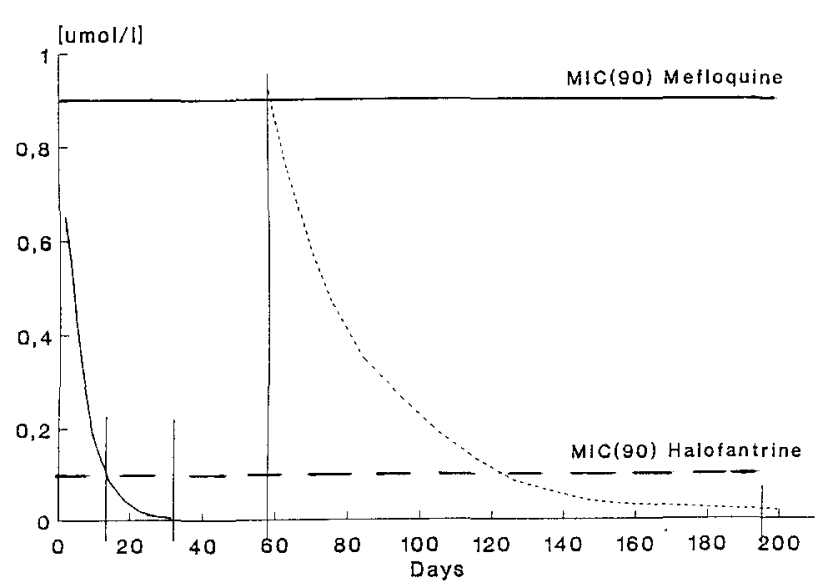

Fig. 3. Pharmacokinetics of mefloquine and halofantrine: duration of subtherapeutic levels. Subtherapeutical Level Halofantrine: Day 13-28; Subtherapeutical Level Mefloquine: Day 57193. - Halof. + Metab. $\left(\mathrm{C}_{\max }=6.4 ; 0.7\right)(\mathrm{T} 0.5=38 \mathrm{~h} ; 103 \mathrm{~h})$; -- Mefloquine $\left(\mathrm{C}_{\max }=6.0\right)(\mathrm{T} 0.5=21 \mathrm{~d}) ;-$ Detection Limit

cemic episodes particularly deleterious in cerebral malaria [18].

\section{Studies on halofantrine}

Up to now, more than 2000 patients with acute malaria have been treated in clinical studies with halofantrine, 1474 of them according to the optimal dosage scheme of $3 \times 500 \mathrm{mg}$ halofantrine at 6-h intervals. Approximately $20 \%$ of the patients were children below the age of 5 years. These studies were conducted between 1985 and 1990 mainly in West and East Africa, Southeast Asia, and the Pacific area, thus in areas with high chloroquine and multidrug resistance [9].

Of the 1474 patients 1315 were infected with $P$. falciparum, 122 with $P$. vivax, and the rest with $P$. ovale, $P$. malariae or mixed infections. Included in the studies were patients with a parasite count between 1000 nd 250000 parasites $/ \mathrm{cm}^{2}$. Exclusion criteria were severe or complicated malaria such as cerebral malaria, acute renal failure, acute liver failure, protracted vomiting, pregnancy, and pretreatment with another antimalarial within the previous 14 days. For each study local ethical review committee approval had been obtained; patients gave written or oral, witnessed, informed consent prior to study entry. Parasitemia was cleared within 7 days in all but eight patients $(0.5 \%)$. The mean fever clearance time was $50.2 \mathrm{~h}$ for $P$. falciparum and $49.6 \mathrm{~h}$ for $P$. vivax infections. The mean parasite clearance time was $57.9 \mathrm{~h}$ and $57.3 \mathrm{~h}$, respectively.
During the observation period of 28 days, the recrudescence of $P$. falciparum parasitemia occurred in 77 patients $(6 \%)$, mainly nonimmune persons or infants below the age of 2 years. However, it cannot be excluded that some of these parasitemias were in fact new infections, as permanent isolation of the patients over 28 days was practically impossible. In $P$. vivax malaria six recrudescences occurred $(5.4 \%)$. Thus, the overall efficacy of halofantrine for treatment of acute malaria can be considered at least $94 \%$, even in areas with unfavorable resistance and high transmission rate.

Halofantrine was in general well tolerated. Fewer than $5 \%$ of the patients experienced mild and transitory diarrhea or irritation of the intestinal tract. Rare events included cough itching, and headache. Laboratory abnormalities such as anemia, thrombocytopenia, and increased transaminases at study entry were considered disease - but not drug - related by the investigators and normalized in parallel to the improvement of the clinical condition. Central nervous symptoms, seizures, or psychotic episodes were not observed in any of the patients during the halofantrine treatment.

Preexisting immunity is one of the major determinants of the therapeutic efficacy of antimalarials. Thus, efficacy in nonimmune patients cannot be deduced from efficacy in the semi-immune [7]. This explains, for example, the higher recrudescence rate in infants, who by definition are considered non-immune.

To evaluate the efficacy of halofantrine in nonimmune individuals we performed a prospective clinical trial in five German institutions specializing in tropical diseases. Included were nonimmune travelers who developed acute malaria after returning from endemic areas with a parasite count of up to $5 \%$. Two different treatments were compared: patients of group A received $3 \times 500 \mathrm{mg}$ halofantrine at 6-h intervals on the day of study entry and patients of group B received a second treatment, with the same dosage, 7 days later. We included 80 patients with imported P. falciparum or $P$. vivax malaria. In more than half of these patients malaria occurred despite prophylaxis with chloroquine, proguanil, or mefloquine. Halofantrine cleared parasitemia in all 80 patients. The clearance time was $53 \mathrm{~h}$ and parasite clearance time $65 \mathrm{~h}$. However, recrudescense occurred in 3 of 27 patients in group A $(11 \%)$ whereas in group B none of the 53 patients developed further episodes of parasitemia [11]. Similar observations were made in a Swiss study with a similar protocol [4] as well as in two French trials $[2,19]$. 
Thus, in nonimmune patients, in whom the majority of imported malaria cases occur in Europe, a secondary treatment course with $3 \times 500 \mathrm{mg}$ halofantrine on day 7 is indicated in addition to the primary therapy on day 1 .

\section{Stand-by therapy}

The worldwide increase in antimalarial drug resistance represents a major problem for the increasing tourism to endemic areas. The malaria incidence in nonimmune travelers to endemic areas - for instance in more than 2 million Germans in 1988 [30] - is higher than expected. When traveling to West Africa, the incidence without chemoprophylaxis is as high as 2.4 cases of clinical disease per 100 travelers per month. A survey of more than 11000 travelers to endemic areas indicated that, although most of the travelers were informed about the risk of malaria at their destination, only $55 \%$ carried out correct and consequent malaria chemoprophylaxis, and less than $5 \%$ correct and consequent exposure prophylaxis [23].

The World Health Organization explicity states that even with correctly performed chemoprophylaxis, complete protection against malaria is not guaranteed [29]. This is especially true for stays in areas with multiple resistance and high transmission rate. In a recent study by the Centers for Disease Control the monthly incidence of $P$. falciparum infection despite correct chloroquine prophylaxis accounted for 2.7 cases per 100 per month in peace corps volunteers in West Africa. Despite consequent mefloquine prophylaxis at biweekly intervals 1/100 nonimmune persons developed acute malaria [10]. In addition, all antimalarials used for chemoprophylaxis are known to induce adverse events in up to $7-45 \%$ of travelers, which consequently leads to poor compliance and less protection [22].

Thus, the World Health Organization recommends for the malaria areas $\mathrm{B}$ and $\mathrm{C}$ that persons take along a curative dose of an antimalarial [29]. The major element of this stand-by concept of the World Health Organization is that travelers to endemic areas carry out a consequent exposure prophylaxis, including the use of impregnated mosquito nets, mosquite repellants, mosquito coils, and appropriate clothing (long sleeves and trousers) [8]. If in spite of these precautionary measures symptoms of malaria occur within 7 days of arrival, and a physician is not immediately available, travelers should take one curative dose of the stand-by drug as self-medication to avoid delaying the start of treatment. In every case, however, a physician must be consulted as soon as possible for confirmation of diagnosis and for possible further treatment. The antimalarial used as stand-by drug must be effective against all forms of malaria, have a low failure rate and a short fever and parasite clearance time, and above all be well tolerated. This is especially important with regard to possible misdiagnosis, as patients may not come to harm by the self-medication. As halofantrine fulfills these requirements, the Working Group on malaria prophylaxis and therapy of the German Society for Tropical Medicine recommends and the Bundesgesundheitsamt (Federal Health Authority) approves halofantrine as first drug for stand-by treatment of acute malaria [8].

\section{References}

1. Anonymous (1989) Halofantrine in the treatment of malaria. Lancet II : 537-538

2. Bernard J, Sarrouy J, Dupasquier I (1990) Traitement du paludisme d'importation a Plasmodium falciparum per l'halofantrine. A propos de 59 observations. Med Trop (Mars) 50:167-171

3. Blauer G (1988) Interaction of ferriprotoporphyrin IX with the antimalarials amodiaquine and halofrantrine. Biochem Int 17:729-734

4. Braendli B, Loutan L, Markwalder K, Bock HL (1991) Treatment of acute malaria with halofantrine in Switzerland - preliminary results of a clinical study. In: Adam D, Lode H, Rubinstein E (ed) 17th International Congress of Chemotherapy, Berlin, June 23-28. Futuramed, Munich

5. Broom C (1989) Human pharmacokinetics of halofantrine hydrochloride. Parasitol Today 5 [Suppl]:15-20

6. Bunnag D, Harinasuta T (1989) Drug combinations for treatment and prophylaxis of multiresistant malaria. Curr J Clin Pharmacol 36 [Suppl]:A13

7. Couland JP, Le Bras J, Matheron S, Moriniere B, Saimot AG, Rossignol JF (1986) Treatment of imported cases of falciparum malaria in France with halofantrine. Trans $R$ Soc Trop Med Hyg 80:615-617

8. Fleischer K, Eichenlaub D, Schönfeld C (1991) Die Malariavorbeugung. Dtsch Arztebl 88:1543-1548

9. Horton J, Parr S, Bokor L, Clemens R (1991) Clinical experience with halofantrine in the treatment of $P$. falciparum malaria (malaria tropica). In: Adam D, Lode H, Rubinstein $\mathrm{E}$ (ed) 17 th International Congress of Chemotherapy, Berlin, June 23-28. Futuramed, Munich

10. Lobel HO, Bernard KW, Williams SL, Hightower AW, Patchen LC, Campbell CC (1991) Effectiveness and tolerance of longterm malaria prophylaxis with mefloquine. JAMA 265:361-64

11. Löscher T, Fleischer K, Kretschmer H, Pohle HD, Weinke T, Köhler B, Schlunk T, Schunck B, Bock HL (1991) Treatment of uncomplicated malaria with halofantrine in nonimmune adults - first clinical results in Germany. In: Adam D, Lode H, Rubinstein E (ed) 17th International Congress of Chemotherapy, Berlin, June 23-28. Futuramed, Munich

12. Milton KA, Edwards G, Ward SA, Orme ML'E, Breckenridge AM (1989) Pharmacokinetics of halofantrine in man: effects of food and dose size. Br J Clin Pharmacol 28:71-77

13. Moran JS, Bernard KW (1989) The spread of chloroquine- 
resistant malaria in Africa. Implications for travellers. JAMA 262:245-248

14. Nosten F, Ter Kuile F, Chongsuphajaisiddhi T, Luxembeurger C, Webster HK, Edstein M, Phaipun L, Thew KL, White NJ (1991) Mefloquin-resistant falciparum malaria on the Thai-Burmese border. Lancet 337:1140-1143

15. Oduola AMJ, Milhous WK, Salako LA, Walker O (1987) Reduced in vitro susceptibility to mefloquine in West African isolates of Plasmodium falciparum. Lancet II:1304 1305

16. Payne D (1987) Spread of chloroquine resistance in Plasmodium falciparum. Parasitol Today $3: 241-246$

17. Peters W, Robinson BL, Ellis DS (1987) The chemotherapy of rodent malaria XLII:halofantrine resistance. Ann Trop Med Parasitol 81:65-67

18. Phillips RE, Looareesuwan S, White NJ (1986) Hypoglycaemia and antimalarial drugs: quinidine and release of insuline. BMJ 292:1319-1321

19. Rouè R, Debord T (1988) Preliminary results. Efficacy, safety of halofantrine in the treatment of a first Plasmodium falciparum malaria attack in adults. In: Proceedings of the XIIth International Congress for Tropical Medicine \& Malaria, Amsterdam, September 19-23. Excerpta Medica International Congress Series, vol 810

20. Schuster BG, Canfield CJ (1989) Preclinical studies with halofantrine in the treatment of multidrug-resistant malaria. Parasitol Today 5 [Suppl]: 3-14

21. Steffen R (1991) The epidemiological basis for the practice of travel medicine. In: 2nd Conference on International Travel Medicine, Program and Abstracts, Atlanta, May 912, p 35

22. Steffen R, Heusser R, Mächler R, Maef U, Somaini B (1989) Malaria chemoprophylaxis in 28712 European travellers to Africa: a follow-up study. In: Steffen R, Lobel HO, Haworth J, Bradley DF (eds) Travel medicine. Springer, Berlin Heidelberg New York, pp 141-144
23. Steffen R, Mächler R, Heusser R, Naef UR (1990) Malaria Prophylaxe bundesdeutscher Afrikareisender. Dtsch Med Wochenschr 115:290-294

24. Suebsaent L, Wernsdorfer WH, Rooney W (1986) Sensitivity to quinine and mefloquine of Plasmodium falciparum in Thailand. Bull WHO 64:759-65

25. Warhurst DC, Diribe OO (1988) Effect of halofantrine on the proton pump of intraerythrozyte Plasmodium berghei. XIIth International Congress for Tropical Medicine \& Malaria, Amsterdam, September 19-23. Treatment of malaria: artemisinine and halofantrine. Excerpta Medica International Congress Series, vol 810

26. Webster HK, Boudreau EF, Pavanand K, Yongvanitchit K, Pang LW (1985) Antimalarial drug susceptibility testing of Plasmodium falciparum in Thailand using a microdilution radioisotope method. Am J Trop Med Hyg 34:228-235

27. Wiselogle FY (1946) A survey of antimalarial drugs 19411945. Edwards, Ann Arbor, pp 309-24

28. World Health Organization (1990) World malaria situation. Wkly Epidemiol Rec 65:189-196

29. World Health Organization (1991) Vaccination and health advice. In: International travel an health. WHO, Geneva

30. World Tourism Organization (1991) World tourism 19701990, WTO, Madrid

Received: August 21, 1992

Accepted: September 25, 1992

Dr. H.D. Nothdurft

Abteilung für Infektions- und Tropenmedizin

Leopoldstrasse 5

W-8000 München 40, FRG 